\title{
Hypertension screening and follow-up in children and adolescents in a Canadian primary care population sample: a retrospective cohort study
}

\author{
Babak Aliarzadeh MD MPH, Christopher Meaney MSc, Rahim Moineddin PhD, David White MD, \\ Catherine Birken MD MSc, Patricia Parkin MD, Michelle Greiver MD MSc
}

\section{Abstract}

Background: Uncertainty exists about the need to screen for hypertension in children and adolescents. Information on current screening and follow-up rates in Canadian community practices is not available. There are no Canadian guidelines on the subject. We sought to identify current rates of pediatric hypertension screening and follow-up in Canada. In addition, we examined patient and provider characteristics associated with rates of blood pressure screening.

Methods: We used electronic medical record data extracted on Apr. 1, 2013, from 79 family practices in Toronto. We identified children seen at least twice between the ages of 3 and 18 years, with at least 6 months between first and last encounter. We used Multivariate Poisson regression analysis to analyze variation in blood pressure measurement rates and associations with patient and physician factors.

Results: We identified 5996 children (62\% of 9667 in total) who had at least 1 blood pressure measurement recorded. Of these children, $14 \%$ had at least 1 abnormal blood pressure measurement, and of those children, only $5 \%$ had a follow-up measurement recorded within 6 months. After adjustment, increases in rates of blood pressure measurements were associated with greater number of encounters (rate ratio $[R R]=1.03,95 \%$ confidence interval $[\mathrm{Cl}] 1.02-1.04, p<0.001$ ), older age at first encounter $(\mathrm{RR}=1.06,95 \%$ Cl 1.03-1.10, $p=0.002)$, and female sex $(R R=1.12,95 \% \mathrm{Cl} 1.03-1.20, p=0.006)$. Obesity or a recorded family history of hypertension were not associated with more blood pressure measurements. Female physicians recorded more blood pressure measurements than did male physicians $(\mathrm{RR}=1.41,95 \% \mathrm{Cl} 1.04-1.89, p=0.02)$.

Interpretation: This screening measure was frequently done and appeared to be incompletely followed up. Clear guidance is needed; guideline developers should consider reviewing this topic.

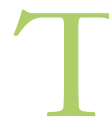
he estimated prevalence of hypertension in children and adolescents is $1 \%-5 \% .^{1}$ The strongest risk factor for pediatric hypertension is obesity; other factors include a family history of hypertension and male sex. ${ }^{2}$ Blood pressure evaluation in children and adolescents includes stratification of hypertensive category using age, sex and height. Prehypertension is defined as blood pressures between the 90th and 95th percentile or greater than $120 / 80 \mathrm{~mm} \mathrm{Hg} .{ }^{1}$ The diagnosis should be confirmed with additional measurements, with follow-up within 6 months. ${ }^{3}$ A blood pressure equal to or greater than the 95 th percentile is defined as being consistent with hypertension. Stable hypertension should be monitored at least every 6 months. Therefore, an abnormal measurement should lead to repeated measurement within a maximal interval of 6 months.

American guidelines recommending the measurement of blood pressure for children between 3 and 18 years of age during every health care episode were published in $2004^{4}$ and endorsed in 2011.5

In 2013, the United States Preventive Services Task Force issued an "I" (insufficient evidence) recommendation for screening for hypertension in children and adolescents. ${ }^{2}$ The task force found no evidence that screening detected children at higher risk of adverse cardiovascular outcomes. ${ }^{2}$

In Canada, the Greig Health Record (for children and adolescents aged 6-17 yr) and the Rourke Baby Record (for

Competing interests: Patricia Parkin is a member of the Canadian Task Force on Preventive Health Care.

This article has been peer reviewed.

Correspondence to: Babak Aliarzadeh, babaka@cpcssn.org

CMAJ Open 2016. DOI:10.9778/cmajo.20150016 
children aged 2-5 yr) have both incorporated periodic blood pressure measurement based on "Fair evidence." no recommendations from the Canadian Task Force on Preventive Health Care or from the Canadian Hypertension Education Program regarding screening for hypertension in children. Owing to the lack of clear recommendations in the US and the absence of evidence-based Canadian guidelines, there is uncertainty about the need to measure blood pressure in asymptomatic children.

We sought to provide evidence on current screening and follow-up that could be used by guideline authors to set priorities for review.

Our objectives were to describe hypertension screening and follow-up in children and adolescents in a Canadian urban primary care population sample. We determined current rates of hypertension screening in children and adolescents, the proportion of patients who receive timely follow-up after an initial abnormal blood pressure reading and the patient and provider characteristics associated with screening rates.

\section{Methods}

\section{Data sources and study population}

This was a retrospective cross-sectional observational study. We used the STROBE checklist to report results. ${ }^{8}$ We used data from 79 primary care providers practising in or around Toronto and participating in the Canadian Primary Care Sentinel Surveillance Network as part of the University of Toronto Practice-Based Research Network (UTOPIAN). Most providers were family physicians; 1 provider was a nurse practitioner. The Canadian Primary Care Sentinel Surveillance Network is Canada's first multidisease electronic medical record (EMR)-based surveillance system. ${ }^{9}$ UTOPIAN is 1 of 10 networks currently participating in the surveillance network. Data were extracted from 3 different EMR applications (Nightingale-on-Demand, Practice Solutions and Bell EMR) on or shortly after Apr. 1, 2013; only data up to Apr. 1, 2013 were included in the study. Networks, including UTOPIAN, run quarterly data extraction on participating primary care practices. Both structured and free-text data are extracted. Extensive validation is done to ensure data extraction is complete and without error. Patients were randomly selected from the study dataset, their information was matched to their electronic charts (front-end EMR), and data extraction queries were adjusted where needed. We used data from the first quarter 2013 data extraction cycle for this study. Data extraction procedures have been described previously. ${ }^{9}$

The study population included all patients flagged as being enrolled in (or rostered to) the practice and indicated as being active (nontransient) in the EMR as of Apr. 1, 2013. All encounters recorded when a patient was between 3 and 18 years of age were extracted. Encounters recorded in the EMR can include phone or email encounters, which were excluded. We only included office visits, because there was an opportunity to measure blood pressure at the office during those encounters. The study sample included children and adolescents with a minimum of 2 office visits with at least 6 months between the first and last visit recorded in the EMR between the ages of 3 and 18 years.

Visits with blood pressure measurements were identified, and the patient's age at the time of visit was calculated. If more than 1 blood pressure record was available for a single date, we calculated the mean systolic and diastolic blood pressures for that visit. If height was not recorded for an encounter with recorded blood pressure, we used the closest height for the same age from other visits if done within 12 months of the encounter. To determine whether a diagnosis of hypertension or a family history of hypertension was entered in the record, we searched each patient's summative health profile and encounter diagnosis records. The summative health profile contains summary data on chronic conditions, medications, allergies, immunizations, and social and family history. ${ }^{10} \mathrm{We}$ searched both coded diagnoses and free-text diagnoses in the summative health profile.

Each provider participating in the network completed a survey on their demographic and practice characteristics. We used these data to describe providers.

\section{Statistical analysis}

We calculated the proportion of the study sample that had at least 1 blood pressure measurement.

For each visit with an available weight and height, we calculated sex and age-adjusted body mass index (BMI) centiles using the most recent World Health Organization growth charts. ${ }^{11,12}$ As currently recommended, ${ }^{5}$ we used the most recent Centers for Disease Control and Prevention growth charts ${ }^{13}$ to calculate age-, height- and sex-adjusted blood pressure centiles for each patient. We then derived the proportion of patients with abnormal blood pressures using the National High Blood Pressure Education Program Working Group on High Blood Pressure in Children and Adolescents' definitions. ${ }^{4}$ For those with an initial abnormal blood pressure, we ascertained the presence of a second blood pressure measurement in the chart within 6 months.

The outcome for the patient-level analysis was the count of the number of blood pressure measurements they had over their follow-up. Multivariate Poisson regression analysis was used to analyze variation in blood pressure measurement rates. Patients were nested within primary care providers; we therefore applied the generalized estimating equation (GEE) method to take into account the correlation between patients clustered within providers. The number of visits that a patient can have is influenced by their duration under care as a patient for a given physician. In this study, we calculated duration under care as the difference between the date of the first visit and the date of the last visit, or the date of data extraction (whichever came first) during the age range of interest. We used the logarithm of the duration under care as the offset in our Poisson regression models. We used regular Poisson regression to fit a model to each unique provider (i.e., we did not use a GEE model). Here, the outcome was a count of the number of blood pressure measurements performed by each provider. The offset was the number of patient-years followup per provider. We adjusted for overdispersion in these 


\section{OPEN}

Research

models by applying the Deviance scale correction factor to the estimated variance-covariance matrix of the regression coefficients. These 2 methods were used to model relations between patient and provider characteristics with rate of blood pressure measurement as the outcome.

All tests were 2 -tailed and a $p$ value of less than 0.05 was considered to be significant. Data were analyzed using SAS version 9.3. The UTOPIAN-Canadian Primary Care Sentinel Surveillance Network project has received ethics approval from the Research Ethics Board of the University of Toronto. All participating primary care providers provided written informed consent for the collection and analysis of their EMR data.

\section{Results}

We identified 9667 eligible patients; of these, 5996 (62\%) had at least 1 blood pressure measurement recorded between the ages of 3 and 18 years. Provider characteristics are shown in Appendix 1 (available at www.cmajopen.ca/content/4/1/E110/ suppl/DC1). The most common rate of recording was every 1-2 years. We found that $11.9 \%$ of pediatric patients were obese (Table 1). In addition, BMI was recorded more often when blood pressures were present in the EMR: $93.5 \%$ of children with a blood pressure recorded also had a BMI recorded, whereas $48.3 \%$ of those with no blood pressure record had a $\mathrm{BMI}$ in their chart (odds ratio [OR] 16.7, 95\% confidence interval [CI] 4.8-5.0, $p<0.001$ ).
In multivariate analyses, increases in rates of blood pressure measurements were associated with a greater number of encounters (rate ratio [RR] 1.03, 95\% CI 1.02-1.04, $p<0.001$ ), older age at first encounter $(\mathrm{RR}=1.06,1.03-1.10, p<0.001)$, and female sex $(\mathrm{RR}=1.12,1.03-1.20, p=0.006)$ (Table 2$)$. Neither obesity nor having a recorded family history of hypertension was associated with an increased rate of blood pressure recording. There was a small association between an increased number of encounters and higher rate of blood pressure screening; older age at first encounter and female sex were also associated with a greater rate of screening. Female physicians recorded blood pressures more often; no other significant associations were found (Table 3).

We were able to calculate blood pressure centiles for 5530 participants (92\% of participants with a recorded BP measurement). We identified 778 patients, or $8 \%$ of the total cohort (14\% of patients with data allowing calculation of blood pressure centiles) who had at least 1 elevated blood pressure measurement; 40 (5\%) of those patients had at least 1 further blood pressure recorded within 6 months. We then limited the analysis to patients with at least 1 visit following the abnormal reading: 660 patients (85\%) were seen at least once after, and $6.1 \%$ had a blood pressure recorded within 6 months. We further limited this to patients seen within 6 months after the abnormal reading: 317 patients (48\%) were seen within 6 months and $13 \%$ had a blood pressure measurement recorded in any visit within the 6-month time frame.

Table 1: Patient characteristics according to rate of blood pressure recording

\begin{tabular}{|c|c|c|c|c|c|c|}
\hline & Overall & $\begin{array}{c}\text { No BP } \\
\text { measurements } \\
\text { on record }\end{array}$ & $\begin{array}{l}\text { BP recorded } \\
\text { every } 4 \text { yr or } \\
\text { less often }\end{array}$ & $\begin{array}{l}\text { BP recorded } \\
\text { every } 2-4 \text { yr }\end{array}$ & $\begin{array}{l}\text { BP recorded } \\
\text { every } 1-2 \mathrm{yr}\end{array}$ & $\begin{array}{c}\text { BP recorded } \\
\text { more than } \\
\text { once/yr }\end{array}$ \\
\hline No. of patients (\%) & 9667 & 3671 (38.0) & $681(7.0)$ & $1529(15.8)$ & $2387(24.7)$ & $1399(14.5)$ \\
\hline $\begin{array}{l}\text { No. of BP measures, } \\
\text { mean } \pm S D\end{array}$ & $1.37 \pm 1.57$ & $0 \pm 0$ & $1.01 \pm 0.10$ & $1.47 \pm 0.62$ & $2.54 \pm 1.36$ & $3.02 \pm 1.89$ \\
\hline $\begin{array}{l}\text { Duration of observation, yr, } \\
\text { mean } \pm \mathrm{SD}<\text { denominator } \\
\text { of rate }>\end{array}$ & $3.25 \pm 1.78$ & $2.82 \pm 1.66$ & $5.33 \pm 1.05$ & $3.95 \pm 1.48$ & $3.48 \pm 1.75$ & $2.23 \pm 1.52$ \\
\hline $\begin{array}{l}\text { No. of recorded encounters } \\
\text { per patient, mean } \pm \text { SD }\end{array}$ & $7.88 \pm 5.57$ & $7.03 \pm 5.11$ & $10.43 \pm 6.31$ & $8.53 \pm 5.58$ & $8.35 \pm 5.64$ & $7.39 \pm 5.64$ \\
\hline $\begin{array}{l}\text { Age at first encounter, yr, } \\
\text { mean } \pm \text { SD }\end{array}$ & $9.26 \pm 4.66$ & $8.39 \pm 4.85$ & $8.01 \pm 3.33$ & $9.37 \pm 4.15$ & $9.64 \pm 4.45$ & $11.34 \pm 4.78$ \\
\hline $\begin{array}{l}\text { Age first } B P \text { recorded, } y r \text {, } \\
\text { mean } \pm S D\end{array}$ & $10.97 \pm 4.44$ & NA & $11.29 \pm 3.73$ & $11.08 \pm 4.22$ & $10.44 \pm 4.48$ & $11.60 \pm 4.81$ \\
\hline Female sex, $N(\%)$ & $5098(52.7)$ & $1802(49.1)$ & $339(49.8)$ & $780(51.0)$ & $1315(55.1)$ & $862(61.6)$ \\
\hline BMI centile, mean $\pm \mathrm{SD}^{*}$ & $\begin{array}{c}58.19 \pm 29.16 \\
(n=7380)\end{array}$ & $\begin{array}{c}57.04 \pm 29.17 \\
(n=1773)\end{array}$ & $\begin{array}{c}58.84 \pm 29.81 \\
(n=606)\end{array}$ & $\begin{array}{c}60.21 \pm 28.90 \\
(n=1424)\end{array}$ & $\begin{array}{c}57.66 \pm 29.08 \\
(n=2271)\end{array}$ & $\begin{array}{c}58.16 \pm 29.15 \\
(n=1306)\end{array}$ \\
\hline Obese, $N(\%)$ & 875 (11.9) & $181(10.2)$ & $83(13.7)$ & $198(13.9)$ & $255(11.2)$ & $158(12.1)$ \\
\hline $\begin{array}{l}\text { Recorded family history of } \\
\text { hypertension, } N(\%)\end{array}$ & $312(3.2)$ & $67(1.8)$ & $12(1.8)$ & $41(2.7)$ & $123(5.2)$ & $69(4.9)$ \\
\hline
\end{tabular}


Table 2: Effect of patient characteristics on rate of blood pressure screening

\begin{tabular}{|c|c|c|c|c|}
\hline \multirow[b]{2}{*}{ Characteristic } & \multicolumn{2}{|c|}{ Bivariate } & \multicolumn{2}{|c|}{ Multivariate } \\
\hline & $\mathrm{RR}(95 \% \mathrm{Cl})$ & $p$ value & $\mathrm{RR}(95 \% \mathrm{Cl})$ & $p$ value \\
\hline No. of recorded encounters & $1.03(1.02-1.04)$ & $<0.0001$ & $1.03(1.02-1.04)$ & $<0.0001$ \\
\hline Age at first encounter & $1.06(1.03-1.08)$ & $<0.0001$ & $1.06(1.03-1.10)$ & 0.0002 \\
\hline Female sex & $1.18(1.10-1.28)$ & $<0.0001$ & $1.12(1.03-1.20)$ & 0.01 \\
\hline Mean BMI centile & $1.11(0.91-1.36)$ & 0.3 & - & - \\
\hline Obesity* & $1.07(0.88-1.31)$ & 0.5 & - & - \\
\hline $\begin{array}{l}\text { Recorded family history of } \\
\text { hypertension }\end{array}$ & $1.44(1.02-2.05)$ & 0.04 & $1.26(0.81-1.95)$ & 0.3 \\
\hline \multicolumn{5}{|c|}{ 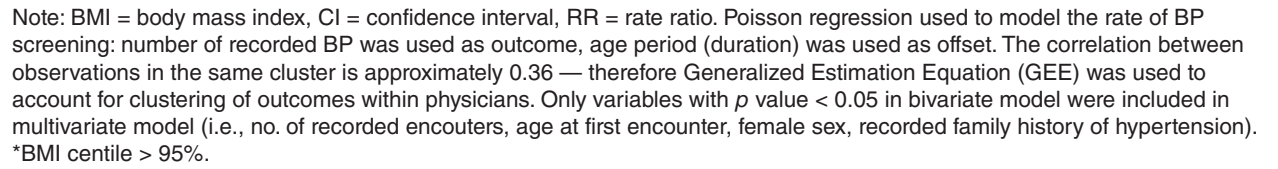 } \\
\hline
\end{tabular}

Table 3: Effect of provider characteristics on rate of blood pressure screening

\begin{tabular}{|c|c|c|c|c|}
\hline \multirow[b]{2}{*}{ Characteristic } & \multicolumn{2}{|c|}{ Bivariate analysis } & \multicolumn{2}{|c|}{ Multivariate analysis } \\
\hline & $\mathrm{RR}(95 \% \mathrm{Cl})$ & $p$ value & $\mathrm{RR}(95 \% \mathrm{Cl})$ & $p$ value \\
\hline $\begin{array}{l}\text { No. of visits caring for } \\
\text { pediatric patients }\end{array}$ & $0.99(0.99-1.00)$ & 0.04 & $1.00(1.00-1.00)$ & 0.2 \\
\hline Female sex & $1.35(1.04-1.75)$ & 0.02 & $1.41(1.04-1.89)$ & 0.02 \\
\hline Age, yr & $0.98(0.97-0.99)$ & 0.02 & $0.98(0.97-1.00)$ & 0.09 \\
\hline Years since graduation & $0.99(0.98-1.00)$ & 0.03 & - & - \\
\hline Practice size & $0.99(0.99-0.99)$ & 0.002 & $1.00(1.00-1.00)$ & 1 \\
\hline $\begin{array}{l}\text { Proportion of practice } \\
\text { aged } 3-18 \mathrm{yr}\end{array}$ & $0.77(0.11-5.15)$ & 0.8 & - & - \\
\hline \multicolumn{5}{|c|}{$\begin{array}{l}\text { Notes: } \mathrm{Cl}=\text { confidence interval, } \mathrm{RR}=\text { rate ratio. Practice size determined as number of enrolled patients in the practice. Poisson } \\
\text { regression used to model the rate of } \mathrm{BP} \text { screening; number of recorded BPs was used as outcome, number of patient years } \\
\text { follow-up per provider was used as offset; } n=79 \text { care providers. Age and years since graduation were highly correlated; therefore } \\
\text { only age was included multivariate model. Only variables with } p \text { value }<0.05 \text { in bivariate model were included in the multivariate } \\
\text { model. Due to high correlation between age and years since graduation, we only included age in multivariate model. }\end{array}$} \\
\hline
\end{tabular}

\section{Interpretation}

In this study, almost two-thirds of children and youths had at least 1 blood pressure measurement recorded as part of an office visit, and $14 \%$ of those with data allowing blood pressure centiles had an abnormal blood pressure measurement on record. However, once an abnormal blood pressure was recorded, timely follow-up was uncommon, even when the patient subsequently visited the office. Known risk factors such as obesity, male sex or a family history of hypertension were not associated with more frequent blood pressure recording.

Blood pressure measurements were recorded in $35 \%$ of ambulatory pediatric visits, $67 \%$ of preventive visits, and $84 \%$ of preventive visits in which overweight or obesity was diagnosed in the US in 2008-2009. ${ }^{14}$ About $8.4 \%$ of children and adolescents in the US had at least 1 elevated blood pressure during a 4 -year period, and $20.9 \%$ of elevated blood pressures led to repeated measurement within 1 month. ${ }^{15} \mathrm{We}$ found similar rates of abnormal blood pressure recording, but much lower rates of follow-up. As with other studies, difficulties in determining abnormal pediatric blood pressures may have led to errors in the recognition of elevated blood pressure, resulting in inconsistent follow-up of abnormal readings. ${ }^{15}$ Determining provider awareness of centiles and barriers to accessing centiles as part of encounters could be the subject of further studies.

Although male patients have higher rates of pediatric hypertension, ${ }^{2}$ female patients were more likely to undergo 
screening in our study, perhaps owing to contraceptive prescribing; measuring blood pressure is recommended before starting the oral contraceptive pill. ${ }^{16}$ Previous studies found that obesity and family history were the most significant predictors of a high blood pressure reading in children ${ }^{14,17}$ and that obese children were more likely to undergo screening. ${ }^{14}$ However, we found no significant association between obesity or a record of a family history of hypertension and blood pressure screening.

Other than provider sex, provider factors such as practice size or proportion of children in the practice population were not associated with rate of screening for hypertension.

\section{Strengths and limitations}

Our study has several strengths. It reflects care in communitybased primary care practices where children are usually seen for routine health services. We extracted data from several different EMR products, suggesting a variety of possible data entry processes in different applications.

Family physicians for this study were not selected randomly, and the sample may not be representative of the general pediatric population across Canada. ${ }^{18}$ There are provincial variations in the age distribution of children for the age groups included in this study. ${ }^{19}$ The sample only includes physicians using EMRs, who tend to be younger than their colleagues who continue to use paper records. ${ }^{20}$ However, the rates of recorded screening and follow-up were similar to studies conducted in the US, likely indicating an acceptable level for the external validity of this study.

A BMI record was missing more frequently among children with no blood pressure measurement recorded. If obese children were more likely to have both BMI and blood pressure recorded, those missing both $\mathrm{BMI}$ and blood pressure may have lower BMI. Therefore, the finding of no association between BMI and blood pressure screening in this study should be treated with caution.

We limited the analysis to patients with at least 2 visits to a family physician to exclude transient patients; this may introduce a selection bias, because children with more severe health conditions or more substantial risk factors may be followed in specialized settings. Alternatively, children with little perceived need for health care may not see a physician at all.

We report on the most common and significant factors (obesity or a family history of hypertension) that affect the prevalence of this condition in children. Other factors or comorbidities, such as diabetes, can affect hypertension and should be examined in future studies.

We found a low rate of follow-up blood pressure measurements; it would be interesting to know whether physicians were aware of blood pressure centiles in addition to crude measurements. This information was not available in patient electronic charts, and we do not know whether care providers have used other methods, outside of the EMR, to calculate blood pressure centiles. Future studies could examine how much the lack of awareness or availability of blood pressure centiles contributes to the lack of follow-up in children with hypertension.

\section{Conclusion}

In this population of children and adolescents, hypertension screening was common, but timely follow-up of abnormal blood pressures was infrequent. Known risk factors such as obesity or a family history of hypertension were not associated with higher rates of screening.

The issues highlighted in this study can be used by guideline authors to set priorities for review topics. Clearly, evidencebased guideline recommendations on pediatric hypertension screening and follow-up are needed.

\section{References}

1. Falkner B. Hypertension in children and adolescents: epidemiology and natural history. Pediatr Nephrol 2010;25:1219-24.

2. Moyer VA. Screening for primary hypertension in children and adolescents: U.S. Preventive Services Task Force recommendation statement. Pediatrics 2013;132:907-14.

3. Redwine KM, Falkner B. Progression of prehypertension to hypertension in adolescents. Curr Hypertens Rep 2012;14:619-25.

4. National High Blood Pressure Education Program Working Group on High Blood Pressure in Children and Adolescents. The fourth report on the diagnosis, evaluation, and treatment of high blood pressure in children and adolescents. Pediatrics 2004;114 (2 Suppl 4th Report):555-76.

5. Expert Panel on Integrated Guidelines for Cardiovascular Health and Risk Reduction in Children and Adolescents. National Heart, Lung, and Blood Institute. Expert panel on integrated guidelines for cardiovascular health and risk reduction in children and adolescents: summary report. Pediatrics 2011; 128(Suppl 5):S213-56.

6. Greig A, Constantin E, Carsley S, et al. Preventive health care visits for children and adolescents aged six to 17 years: the Greig Health Record - Executive Summary. Paediatr Child Health 2010;15:157-62.

7. Rourke Baby Record. Available: www.rourkebabyrecord.ca (accessed 2016 Jan. 4).

8. von Elm E, Altman DG, Egger M, et al. The Strengthening the Reporting of Observational Studies in Epidemiology (STROBE) Statement: guidelines for reporting observational studies. Int 7 Surg 2014;12:1495-9.

9. Birtwhistle R, Keshavjee K, Lambert-Lanning A, et al. Building a pan-Canadian primary care sentinel surveillance network: initial development and moving forward. 7 Am Board Fam Med 2009;22:412-22.

10. Medical records. Policy number 4-12. Toronto: The College of Physicians and Surgeons of Ontario. Available: www.cpso.on.ca/Policies-Publications/Policy/ Medical-Records (accessed 2016 Jan. 4).

11. WHO child growth standards: methods and development. Geneva: World Health Organization; 2006. Available: www.who.int/childgrowth/standards/ technical_report/en/ (accessed 2016 Jan. 4).

12. Application tools. Geneva: World Health Organization. Available: www.who. int/growthref/tools/en/ (accessed 2016 Jan. 4).

13. CDC growth charts: United States. Atlanta (GA): Centers for Disease Control and Prevention; 2010. Available: www.cdc.gov/growthcharts/ (accessed 2013 June 23).

14. Shapiro DJ, Hersh AL, Cabana MD, et al. Hypertension screening during ambulatory pediatric visits in the United States, 2000-2009. Pediatrics 2012;130:604-10.

15. Daley MF, Sinaiko AR, Reifler LM, et al. Patterns of care and persistence after incident elevated blood pressure. Pediatrics 2013;132:e349-55.

16. Selected practice recommendations for contraceptive use, 2 nd ed. Geneva: World Health Organization; 2005.

17. Fuly JT, Giovaninni NP, Marcato DG, et al. Evidence of underdiagnosis and markers of high blood pressure risk in children aged 6 to 13 years. 7 Pediatr (Rio 7) 2014;90:65-70.

18. Paediatricians in Canada: frequently asked questions. Ottawa: Canadian Paediatric Society. Available: www.caringforkids.cps.ca/handouts/paediatricians_in_ canada (accessed 2016 Jan. 4).

19. The Canadian population in 2011: age and sex. Ottawa: Statistics Canada; 2015. Available: www12.statcan.ca/census-recensement/2011/as-sa/98-311x/98-311-x2011001-eng.cfm (accessed 2016 Jan. 4).

20. Results for family physicians. Mississauga: National Physician Survey; 2013. Available: nationalphysiciansurvey.ca/wp-content/uploads/2013/09/2013-FPGP -EN-Q12.pdf (accessed 2016 Jan. 4).

Affiliations: University of Toronto Practice Based Research Network (Aliarzadeh, Meaney, Moineddin, White, Greiver), Department of Family Medicine at University of Toronto (Meaney, Moineddin, White, Greiver), The Hospital for Sick Children, Department of Paediatric Medicine and the Paediatric Outcomes Research Team (Parkin, Birken), University of Toronto, Department of Paediatrics (Parkin, Birken), Toronto, Ont. 
Contributors: All of the authors contributed to conception and design. Babak Aliarzadeh was responsible for acquisition of data. Christopher Meaney, Babak Aliarzadeh and Rahim Moineddin contributed substantially to the analysis of data. Patricia Parkin and Catherine Birken provided content-specific expertise on paediatric hypertension. Michelle Greiver, David White and Babak Aliarzadeh provided expertise in the areas of primary care and use of EMR data. Babak Aliarzadeh and Michelle Greiver drafted the initial version of the article. All authors contributed to the interpretation of data. All authors reviewed and revised the article for important intellectual content, gave final approval of the version to be published and agree to act as guarantors of the work.
Funding: Dr. Greiver holds an investigator award from the Department of Family and Community Medicine, University of Toronto.

Disclaimer: The Canadian Primary Care Sentinel Surveillance Network is a committee of the College of Family Physicians of Canada and is funded through a contribution agreement with the Public Health Agency of Canada. The views expressed herein do not necessarily represent the views of the Public Health Agency of Canada.

Supplemental information: For reviewer comments and the original submission of this manuscript, please see www.cmajopen.ca/content/4/1/ E110/suppl/DC1 